Western University

Scholarship@Western

Department of Economics Research Reports

Economics Working Papers Archive

1994

\title{
Toilet Cleaning and Department Chairing: Volunteering a Public Service
}

Marc Bilodeau

Al Slivinski

Follow this and additional works at: https://ir.lib.uwo.ca/economicsresrpt

Part of the Economics Commons

Citation of this paper:

Bilodeau, Marc, Al Slivinski. "Toilet Cleaning and Department Chairing: Volunteering a Public Service." Department of Economics Research Reports, 9402. London, ON: Department of Economics, University of Western Ontario (1994). 
ISSN : 0318-725X

ISBN : 0-7714-1618-0

\author{
RESEARCH REPORT 9402 \\ Tollet Cleaning and Department \\ Chairing: volunteerine a \\ Public Service \\ by \\ Marc Bilodeau \\ and
}

Al Silvinski

Pebruary 1994

Department of Economics

Social Science Centre

Un1versity of Western Ontar10

London, Ontar10, CANADA

N6A $5 \mathrm{C2}$ 


\title{
TORET CLEANING AND DEPARTMENT CHARING:
}

\author{
VOLUNTEERNG A PUBLIC SERVICE*
}

\author{
Mare BLODEAU \\ Dépanement d'Economique \\ Universite de Sherbroake \\ Sherbrooke (Quebec) \\ CANADA JIK 2RI \\ Tel.:(819)821-7232
}

\author{
Al SLIVINSKI \\ Departoment of Economics \\ Universiry of Westem Orsario \\ London (Ontario) \\ CANADA N6A SC2 \\ Tel.:(519)679-2111 ex 5293
}

Revised February 1994

\begin{abstract}
Who will do a job that nobody wants but that someone bas to do? The search for a voluateer is modelled as a war of attrition in which everyone is tempted to just wait for someone else to do it. We show that the volunteet will be, ceteris paribus, the individual for whom the benefivecot ratio of performing the public service is largen, the one most impatient to consume it, or the one who stands to benefit from it the the loagest.
\end{abstract}

Correspondence 10: Mare Bilodeau, Département d'Economique, Université de Sherbrooke, Sherbrooke, Québec JIK 2RI. Canada

- This paper is dedicated to profs. Gerald Roy and Jim Davies who have graciously agreed to chair the Departments of Economics at the Universite de Sherbrooke and the University of Western Ontario respectively. The firt author acknowledges financial suppon from the Social Sciences and Humanities Research Council of Canada. 


\section{INTRODUCTION}

Many activities that benefit all members of a group are most efficiently performed by a single person. Some examples are getting up at night to quiet a crying baby, cleaning shared toilets, and chairing a university department. These activities are public services, but their cost is bome entirely by the individual performing them. Everyone therefore has strong incentives to free ride by letting someone else do it.

One manifestation of the reluctance to take on such a job is simply that individuals will wait for someone else to do it. The longer one waits, the greater the likelihood that someone else will do it. But until someone volunteers, everyone is kept awake by the crying baby, endures increasing untidiness, or mounting administrative chaos. The downside of waiting longer is simply that if everyone does so, then all must suffer in the meantime. Who will end up doing a job that nobody wants but that someone has to do?

To answer this question, we build a model in which a group of individuals would like to consume a public service (or a nonincremental public good) which can be provided entirely by a single individual. The waiting game induced among them is a special case of a general class of games known as "wars of attrition". A similar approach is used by Bliss and Nalebuff(1984). They assume that everyone would get the same value from a public good but have different costs of providing it, and that this cost is private information for each individual. They then use the revelation principle to show that there exists an equilibrium in which individuals choose a waiting time that is positively related to their costs, so that the lowest cost individual eventually reveals his type by volunteering first. However Bliss and Nalebuff's analysis does not give a definite answer to the question posed above because stationary wars of attrition have an infinite number of subgame perfect equilibria' ${ }^{\prime}$, and there is a subgame-perfect equilibrium in which anyone volunteers. To determine who will volunteer, either a uniqueness result or a reasonable equilibrium selection argument is needed.

We find that in a very general complete information game, multiplicity of equilibria depends crucially on the (simplifying) assumption that individuals have an infinite horizon. If we assume instead that individuals have a finite horizon, the game has a unique subgame-perfect equilibrium outcome in which, ceteris paribus, the individual with the highest benefit/cost ratio from providing the public service, the largest rate of time preference, or the longest time horizon, volunteers immediately and everyone else waits. This remains true even when the time horizon tends to infinity. Since the infinite horizon game is the limit of the set of finite horizon games, this outcome stands out even in infinite horizon games. 
Finally, we generalize the game further to look at the case where individuals care about how the job in question will be done. That is, if different individuals would do the job differently, it may then matter to each who will perform the service if they themselves do not. We show that, when everyone would still rather let anyone else do it than do it themselves, such preferences are irrelevant, in the sense that it is still that person whose benefit/cost ratio of performing the service is highest that will volunteer immediately to do the job.

MODEL

Consider a group of $n+1$ individuals. Suppose that until the public service is performed, individual $i$ gets a utility flow of $v_{i}$, and that once the public service is supplied, his utility flow from that time forward is $u_{i}>v_{i}$. Performing certain public services, like chairing an academic department is often accompanied by a variety of perks, such as prestige, pay increases, a larger office and reduced teaching loads. If perks are attractive enough to turn the job into a plum, finding a volunteer to do it will not be a problem. We are interested here in situations in which perks are not important enough to offset the cost of performing the public service, and so we let $C_{i}>0$ be the present discounted value of the net cost to individual $i$ if he supplies the public service. Assume also that individual $i$ discounts the future at rate $r_{i}$. Because no one with a cost $C_{i}>$ $\left(u_{i}-v_{i}\right) / r_{i}$ would ever provide the service, assume without loss of generality that $C_{i}<\left(u_{i}-v_{i}\right) / r_{i}$, for all $i$. Assume also that everyone's costs and benefits are common krowledge.

A very simple way to proceed would be to suppose that everyone makes a simultaneous one-time choice from the strategy set $\{$ volunteer, do not volunteer\}, with the palyoff to being the only volunteer being $u_{i} / r_{i}-C_{i}$, and the payoff to everyone else being $u_{i} / r_{i}$. If no one volunteers, everyone gets the payoff $v_{i} / r_{i}$. If we further assume that the payoff to volunteering with someone else is any $w_{i} \leq u_{i} / r_{i}{ }^{2}$ then the game is a static game of chicken with $n+1$ players. It has many pure strategy Nash equilibria in which anyone volunteers. For example, suppose everyone but $i$ decides not to volunteer, then it is optimal for $i$ to volunteer to get $u_{i} / r_{i}-C_{i}$ instead of $v_{i} / r_{i}$, and if he does, it is optimal for everyone else not to. This is true for any $i$, so this simple static model is too crude to yield arl answer to the question: who will volunteer?

A fruitful way to enrich the model is to add a dynamic element by allowing individuals the possibility of waiting for some time before volunteering. The point of waiting is of course to let someone else volunteer first, but waiting can be costly because until someone performs the service, no one can enjoy its benefits. Economic intuition

2 Plausible specifications could be for example, that each volunteer incurs his full cost $C_{l}$ regardless of how many others volunteer, or that if $\boldsymbol{m}$ individuals volunteer, each receives a payoff of $u_{i} / r_{l}-C_{i} / m$. 
suggests that differences in how much each stands to benefit from the public service, in the costs of performing the service, and in the rates of time preferences should then be reflected in the length of time individuals are willing to wait.

In the reduced strategic form of this game, a pure strategy is a time $t \in[0, \infty)$ at which to volunteer if no one else has. The game ends and the public service is performed once anyone volunteers. In the extensive form, a strategy must also specify whether a player would volunteer at any $t$ in the eventuality that no one had volunteered up to that point. In particular, strategies must specify what a player would do even at times that would be reached with probability zero given everyone's strategies. For example, if someone volunteers with probability 1 at $t=0$, strategies must also specify what everyone would do if any $t>0$ is reached.

Now, if the public service is performed by someone else at time $t$, individual $i$ 's payoff would be $F_{i}(t)=\frac{v_{i}}{r_{i}}\left(1-e^{-r_{t}}\right)+\frac{u_{i}}{r_{i}} e^{-r t}$. Suppose also that the cost of performing the public service includes two separate components: a one-time utility $\operatorname{cost} f_{i}$, and a net utility flow of costs minus perks $c_{i}$ incurred for a period of time $\Delta$ that may extend to the end of the time horizon. The total cost of volunteering at time $t$ is therefore $\left.c_{r}(t)=f f^{-r_{s}}+\frac{c_{l}}{r_{l}} e^{-r_{r}}-e^{-r_{i}(k+\Delta)}\right)$. Assume that $u_{i}-c_{i}-r f_{i}>v_{i}$ for all $i$, so everyone would still rather perform the public service than do completely without it. Let $L_{i}(t)=F_{i}(t)-C_{i}(t)$ be the payoff to $i$ if she is the only one to volunteer at time $t$, and let $S_{i}(t)$ be $i$ 's payoff if she volunteers simultaneously with some others, where $L_{i}(t) \leq S_{i}(t)<F_{i}(t){ }^{3}$ Then $S_{t}=\lim _{t \rightarrow \infty} L_{i}(t)=\lim _{n-\infty} F_{i}(t)=\frac{v_{t}}{r_{t}}$ is her payoff if no one ever volunteers.

Since $L_{i}(t)>F_{i}(t)$ for any $t$, this game is an $n+1$ player version of a continuoustime war of attrition. Hendricks et al.(1988) provide a complete characterization of all the subgame perfect equilibria for this class of games when there are two players. Extension to games resulting in one loser and $n$ winners is immediate. So using their results, we can state the following proposition:

Proposition 1: For every individual, there is a subgame perfect equilibrium outcome in which only that individual volunteers immediately.

3 For example, we could have $S_{l}(t)=\lambda L_{l}(t)+(1-\lambda) F_{i}(t)$, where $\lambda \in(0,1)$. The exact specification is not important 
The proofs of all propositions are collected in a mathematical appendix at the end of the paper. Intuitively, since $L_{i}(0)>S_{i}$, an individual is always better off volunteering imrnediately than doing completely without the public service if no one else volunteers. So suppose no one else ever volunteers, then it is optimal for $i$ to volunteer immediately, and since $i$ volunteers immediately, no one else can do better by changing their strategies. Verifying subgame perfection requires defining strategies for the extensive form game. If everyone but $i$ adopts the strategy of never volunteering, then the best $i$ can do is to volunteer with probability 1 if any $t$ is ever reached. But given such a strategy by player $i$, no one else has any incentive to change his strategy, so this is a subgame perfect equilibrium.

Neither the application of trembling-hand perfection nor of proper perfection succeed in eliminating any of these equilibrium outcomes. The reason is that for an equilibrium to pass these tests, it is sufficient to find any technology of errors such that a player's strategy remains optimal when others are susceptible of error. So for example, consider an equilibrium in which $i$ never volunteers and $j$ always volunteers. If $j$ is susceptible of error and only volunteers with $99 \%$ probability at each $t, i$ may be content to continue never volunteering. And if $i$ is susceptible of error and volunteers with 1\% prcbability over the interval $[0, \infty), j$ may remain better off always volunteering.

So even this dynamic model admits subgame perfect equilibria in which anyone might volunteer. Explicit consideration of the dynamics of the situation does not seem to make the answer more apparent. However, consider altering the game to one in which inclividuals have a finite time horizon, $T_{i}$. Then the relevant payoffs become

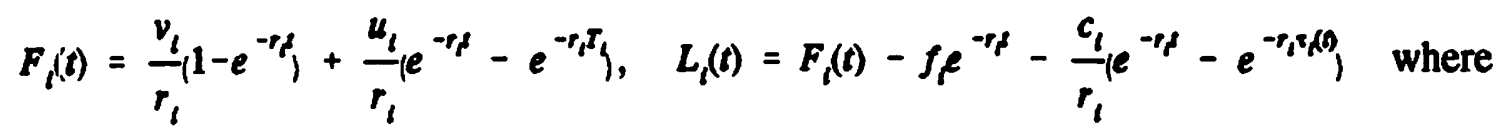
$\tau_{i}(t)=\min \left\{T_{i}, t+\Delta\right\}$, and $S_{t}=\frac{v_{t}}{r_{i}}\left(1-e^{-r_{i} T_{j}}\right.$. So for $t \geq T_{i}-\Delta, L_{i}(t) \geq S_{i}$ if and only if $\left(\frac{u_{t}-v_{t}-c_{t}}{r_{t}}\right)\left(e^{-r_{t}}-e^{-r_{r} r_{q}} \geq f e^{-r_{t}}\right.$. Since the left-hand side of this latter inequality goes to 0 as $t \rightarrow T_{i}$ while the right-hand side goes to $f_{f} e^{-r_{i} T_{i}}>0$ if $f_{i}>0$, then there exists a $t_{i}<T_{i}$ such that $L_{i}(t)<S_{i}$ for all $t>t_{i}$.

The important manner in which this differs from the infinite horizon game is that when individuals have a finite horizon, the game is not stationary and there comes a point in time, $t_{i} \forall i$, when it is no longer worth performing the job because the benefits will be felt for only a short time after. Beyond that point, it is a dominant strategy for $i$ to never 
volunteer. Solving for the $t_{i}$ for which $L_{i}(t)=S_{i}$, we find $t_{t}=T_{t}-\frac{1}{r_{t}} \ln \left(\frac{B_{t}}{B_{t}-1}\right)$, where $B_{1}=\left(u_{l}-v_{l}-c_{l}\right) / r_{i} f_{l}$ is $i$ 's benefit/cost ratio of providing the public service. Given our assumptions, $B_{i}>1$, so $t_{i}<T_{i}$ for all $i$, and $t_{i}$ is increasing in $B_{i}, T_{i}$ and $r_{i \cdot}$. Note that if $T_{i}$ is short enough, $t_{i}<0$ is possible, in which case it is a dominant strategy for $i$ to never volunteer. To make the game interesting, assume that at least some individuals have a long enough time horizon to have a positive $t_{i}$. The following proposition is proved in the appendix.

Proposition 2: Generically', when individuals have a finite horizon, the unique subgame perfect equilibrium outcome has the individual with the largest value of $t_{t}$ volunteering immediately.

Intuitively, since $t_{i}$ is the time beyond which it is a dominant strategy for $i$ not to volunteer, then if $i$ has not volunteered by $t_{i}$, he never will. We can order individuals according to their $t_{i}$ values, with 0 being that individual with the largest value of $t_{i}$, individual 1 the second highest, etc. Then at time $t_{1}, \# 0$ can deduce that no one else will volunteer later, so he is better off volunteering then. But then there is a time before $t_{1}$ when everyone else is better off waiting for $\# 0$ to volunteer at $t_{1}$. Therefore when that time is reached, $\# 0$ is better off volunteering then. By backward induction, \#0 will volunteer immediately and everyone else will wait.

This implies that, ceteris paribus, the individual with the highest benefit/cost ratio of providing the public service is the most likely to volunteer. In particular, if they value the service equally, those who can provide it at the lowest cost are the most likely to volunteer. Similarly, the individuals who stand to gain the most from the public service, in the sense that $u_{i}-v_{i}$ is large, will also be more likely to volunteer. If all other parameters were identical across individuals, the most impatient (i.e., the individuals with the highest rate of time preference) would volunteer first. And finally, other factors being equal, the individual with the longest horizon will volunteer first. This means that in an academic department, those close to retirement are less likely to volunteer for chairmanship than their more junior colleagues who have greater stakes in their department's future prosperity. These results are in accord with what would have been expected intuitively in such a situation.

One might hold that assuming a finite time horizon is a reasonable way to model the type of situation considered here. After all, humans have finite lives, careers in an academic department last only a finite number of years, and the need for many public

\footnotetext{
5 Since we cannot rule out the possibility that two or more individuals are tied with the largest value of $t_{i}$, the subgame perfect equilibrium outcome is only 'almost always' unique.
} 
seivices vanishes if they are not provided within a finite time frame, as when a group of bystanders are deciding whether to enter a buming building to rescue someone. The assumption that individuals have an infinite horizon, as in Bliss and Nalebuff(1984), is most often made for simplicity and plays no essential role in the model. But even if one viewed an infinite time horizon as the appropriate model, it is only at the limit, when $T_{i}=\infty \forall i$, that the set of subgame-perfect equilibrium outcomes explodes. Since the infinite horizon game is the limit of a sequence of finite horizon games, and each finite horizon game has a unique subgame perfect equilibrium outcome in which the individual with the largest $t_{i}$ volunteers, this outcome stands out even when $T_{i}=\infty \forall i$, as its most plausible solution.

Note also that a necessary condition for the existence of a unique subgame perfect outcome in the finite horizon game is the presence of a positive fixed cost, $f_{i}$. Without such a cost, no matter how small, the critical times $t_{i}$ cannot be defined. But here again, the game with $f_{i}=0$ could be seen as the limit of a sequence of games with $f_{i}>0$, each of which has a unique perfect equilibrium outcome, so this outcome stands out even when $f_{i}=0$ and the number of equilibrium outcomes becomes large.

The above model is very general but does abstract from the fact that sometimes, individuals may care about how the service will be performed, and so if different individuals would do it differently, it could matter to them who performs the service if they do not. For example, an academic department's chairperson can influence a department's intellectual orientation by giving priority to teaching or research, and by controlling how the department's funds will be spent. Then, someone who does not volunteer avoids the cost of performing the public service, but at the cost of letting someone with different preferences or competence do it in a way which he does not completely approve.

Such considerations can be incorporated into the model by letting $u_{i j}$ be the payoff to $i$ if $j$ does the job. Letting the flow cost $c_{i}=0$ for simplicity, then $L_{l}(t)=\frac{v_{t}}{r_{l}}\left(1-e^{-r_{l}}\right)+\frac{u_{u}}{r_{l}} e^{-r_{s}}-f_{l} e^{-r_{t}}$ and $F_{y}(t)=\frac{v_{t}}{r_{l}}\left(1-e^{-r_{l}}\right)+\frac{u_{y}}{r_{l}} e^{-r_{s}}$ for $j \neq i$. Assuming that $u_{u}>u_{y}>u_{u}-r f_{t}>v_{l}$, so that $i$ would always prefer to do the job himself if it were not costly to do so, but given the costs would still rather let anyone else do it than volunteer, then $F_{i j}(t)>L_{i}(t)$ for all $i, j, t$. Letting $S_{j}(t)$ be the payoff to $i$ if he volunteers simultaneously with $j$, and assuming that $S_{i t}(t)<F_{j j}(t)^{6}$, the infinite horizon game is still a stationary war of attrition for which there will be $n$ winners and one loser. The difference is that individuals also care about the identity of the loser. This game will

6 Here we simply let $S_{i s}(t)$ refer to the payoff if $i$ volunteers simultaneously with any subset $\boldsymbol{H}$ of individuals. Again, it is only important that this inequality hold for any such subset. 
again have perfect equilibria in which anyone volunteers immediately.

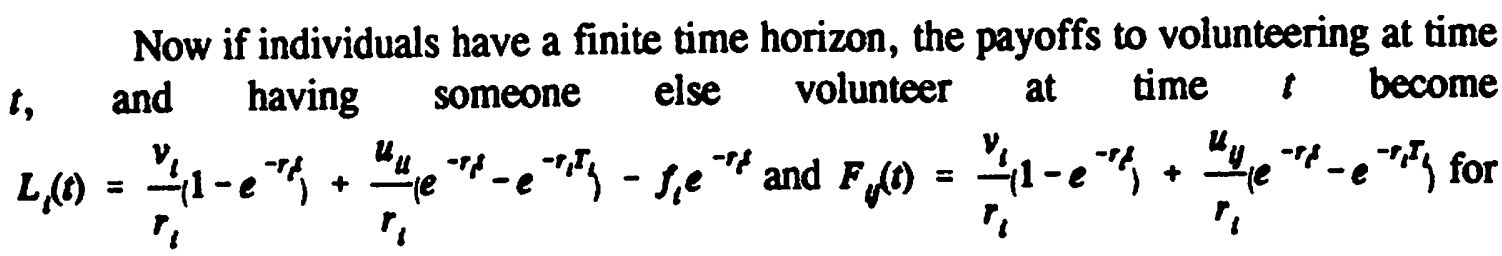
$j \neq i$, and there is again a unique point in time $t_{i}$ for each $i$ such that $L_{i}\left(t_{i}\right)=S_{i}$. However, no terms involving $u_{i}$ appear in the expression for this $t_{i}$, since if no one ever volunteers, there is no issue of 'identity'. Therefore, the argument of Proposition 2 again implies that the unique subgame perfect equilibrium outcome still has the individual with the largest $t_{i}$ volunteering immediately. Preferences regarding how the job should be done play no role in determining the equilibrium outcome. The decision of whether to volunteer or not is independent of whether $i$ prefers that the service be performed by $j$ rather than $h$ if he does not do it himself.

Note however that this result hinges on the assumption that $u_{i j}>u_{i j}-r f_{i}$ for all $i, j$. If this inequality is reversed for some $i, j$, then individuals would no longer always prefer to let anyone else perform the public service, and we might see someone running for a chairmanship simply to preempt someone else from doing it. The analysis of this case would likely be interesting, but since we would then have $L_{i}(0)>F_{i j}(0)$, the game would no longer be a war of attrition, and so analysis of its equilibria would require a different set of techniques than are used here.

\section{Concuusion}

Who will volunteer for a job that everyone would rather let someone else do? To answer this question, we have modelled the search for a volunteer as a war of attrition in which everyone is tempted to just wait for someone else to do it. Though the infinite horizon version of this game has many perfect equilibria in which anyone could volunteer, the unique subgame perfect equillibrium outcome of the finite horizon game is that the volunteer will be, ceteris paribus, the individual for whom the benefit/cost ratio of performing the public service is the largest, the one who is the most impatient from consuming it, or the one who stands to benefit from it the longest. Further, as long as everyone would still rather let anyone else do the job than do it themselves, preferences about how the job should be done and by whom are irrelevant to the decision of whether to volunteer or not. 


\section{APPENDDX}

\section{Proof of proposition 1:}

By definition $L_{i}(0) \geq S_{i}$, so condition (b)(i) of theorem 1 of Hendricks et al.(1988) is statisfied. Therefore there is an equilibrium in which someone volunteers immediately with probability 1 and everyone else wait with probability 1.

By definition there is no $t$ for which $L_{k}(t)<S_{i}$ for any $i$, and for all $i$ we also have $L_{(C)}>S_{i}$, so condition (b) of theorem 4 of Hendricks et al.(1988) is satisfied. Therefore there is a subgame perfect equilibrium in which any $i$ volunteers immediately with probability 1.

QED

\section{Proof of proposition 2:}

Let $t_{0}>t_{1}>\ldots>t_{n}$. At any $:>t_{0,}$ no one will volunteer. At any $t \in\left(t_{1}, t_{0}\right], \# 0$ can deduce that no one else will ever volunteer. But since $L_{0}(t)>S_{0}\left(T_{0}\right) \forall t \in\left(t_{1}, t_{0}\right)$, th's subgame-perfect strategy must be to volunteer if any such $t$ is reached. At any $t \in\left(t_{2}, t_{1}\right]$, both $\# 0$ or $\# 1$ might volunteer, but at a $t$ sufficiently close to $t_{1}, F_{1}\left(t_{1}\right)>L_{1}(t)$, and $\# 1$ will prefer to wait for $\$ 0$ to volunteer at $t_{1}$. Therefore, in any subgame-perfect equilibrium, $\# 0$ must volunteer at any $t \in\left[t^{2}, t_{0}\right)$. By induction, the unique subgame perfect equilibrium outcome has $\sharp 0$ volunteering at $t=0$ and everyone else never volunteering.

QED

\section{REFERENCES}

Bliss, Christopher, and Nalebuff, Barry, (1984), "Dragon-Slaying and Ballroom Dancing: The Private Supply of a Public Good", Journal of Public Economics, 25, p 1-12

Hendricks, Ken; Weiss, Andrew, and Wilson, Charles, (1988), "The War of Attrition in Continuous Time with Complete Information", International Economic Review 29, p. 663-680. 